\title{
CONTRIBUIÇÃO DE ETAPAS DO BENEFICIAMENTO NA QUALIDADE FISIOLÓGICA DE SEMENTES DE DOIS HÍBRIDOS DE MILHO ${ }^{1}$
}

\author{
ROBERTA LEOPOLDA FERREIRA², MARCO EUSTÁQUIO DE SÁ3
}

\begin{abstract}
RESUMO - O objetivo do trabalho foi verificar a qualidade fisiológica de sementes durante as após várias etapas do beneficiamento de dois híbridos de milho e a contribuição de cada equipamento na melhoria da qualidade das sementes. Foram coletadas amostras de sementes chatas de dois híbridos, peneira $22 \mathrm{~L}$, na recepção e após as fases de secagem, pré-limpeza, limpeza, separação por espessura, mesa gravitacional e quando as sementes encontravam-se prontas para embalagem, totalizando sete etapas do beneficiamento mais uma testemunha (colheita e debulha manual). Realizou-se o teste de germinação, análise de pureza, primeira contagem, índice de velocidade de germinação, envelhecimento acelerado, teste de tretrazólio, teste de frio, comprimento de raiz primária e parte aérea, matéria seca de plântulas, emergência em solo e deterioração controlada. O delineamento experimental foi inteiramente casualizado, com quatro repetições por tratamento/ teste, analisando-se cada híbrido separadamente. O beneficiamento promoveu melhoria na qualidade das sementes, sendo que aquelas obtidas após a mesa gravitacional e as prontas para ensaque, foram no conjunto de observações, as que apresentaram melhor qualidade fisiológica.
\end{abstract}

Termos para indexação: Zea mays L., vigor, mesa gravitacional, germinação.

\section{EFFECT OF SEED PROCESSING ON THE PHYSIOLOGICAL SEED QUALITY OF TWO CORN HYBRIDS}

\begin{abstract}
The objective of this study was to verify the effects of the various stages of seed processing on physiological seed quality. Flattened seeds of two corn hybrids were collected with a $22 \mathrm{~L}$ sieve on reception and subjected to seven processing stages, including drying, precleaning, cleaning, separation by thickness and the gravity table. The control treatment involved only harvesting and manual threshing. The following tests were done: standard germination, seed purity, first count, velocity germination index, accelerated ageing, seed viability (tetrazolium), cold test, radical length, hypocotyl length, seedling dry matter, soil emergence and controlled deterioration. The experimental design was entirely randomized with four repetitions. Seed processing improved seed quality and those seeds obtained after passing through the gravity table and those ready for bagging showed the best physiological quality.
\end{abstract}

Index terms: Zea mays L., vigor, gravity table, germination.

\footnotetext{
${ }^{1}$ Submetido em 10/09/2009. Aceito para publicação em 06/08/2010. Parte da dissertação de mestrado do primeiro autor, apresentada à Universidade Estadual Paulista "Júlio de Mesquita Filho", Faculdade de Engenharia, Campus de Ilha Solteira (FE/Unesp), Programa de Pós-Graduação em Agronomia.
}

${ }^{2}$ Eng. Agronôma, Universidade Estadual Paulista "Júlio de Mesquita
Filho", Faculdade de Engenharia, Caixa Postal 31, CEP 15.385-000 Ilha Solteira, SP. E-mail: roberta.1f@bol.com.br

${ }^{3}$ Eng. Agronômo, Dr. Professor - Universidade Estadual Paulista "Júlio de Mesquita Filho", Faculdade de Engenharia, Caixa Postal 31, CEP 15.385-000 Ilha Solteira, SP. mesa@agr.feis.unesp.br. 


\section{INTRODUÇÃO}

A qualidade da semente pode ser afetada por operações decorrentes da colheita, secagem, beneficiamento, armazenagem e semeadura, além dos aspectos genéticos e de cultivo. Tais fatores incluem temperaturas extremas durante a maturação, flutuações das condições de umidade ambiente, tais como secas, deficiências na nutrição das plantas, ocorrência de insetos, além da adoção de técnicas inadequadas de colheita, secagem e armazenamento (França Neto et al., 1994), bem como do beneficiamento.

O beneficiamento de sementes de milho é uma operação altamente especializada do ponto de vista operacional, quando comparado com o de outras espécies de grandes culturas. A semente de milho normalmente é colhida, manuseada, despalhada e secada na espiga, para ser debulhada, limpa e classificada. A classificação é necessária devido à grande variação em tamanho, forma e qualidade das sementes, em função da posição na espiga. Além disto, a separação por densidade pode ser recomendada como acabamento para melhorar a qualidade fisiológica (germinação e vigor) do lote de sementes.

Segundo Fessel et al. (2003), após as sementes passarem pela mesa de gravidade ocorre aumento na porcentagem de germinação, primeira contagem da germinação, porcentagem de plântulas normais no teste de frio, no envelhecimento acelerado, emergência em campo e aumento no índice de velocidade de germinação do lote. Os autores observaram que a mesa de gravidade interfere positivamente na qualidade fisiológica do lote, ao remover as sementes de menor densidade, quebradas e atacadas por patógenos, proporcionando assim um melhor desempenho fisiológico das sementes (Fessel et al., 2003). Tal fato demonstra os efeitos benéficos do beneficiamento sobre a qualidade das sementes. Assim, observa-se que as várias etapas do beneficiamento são eficientes para melhorar a qualidade fisiológica de lotes de sementes.

Amaral et al. (1984) verificaram que a utilização da máquina de ar e peneiras e da mesa de gravidade elimina materiais indesejáveis, aumentando a pureza física e sanitária de lotes de sementes de ervilha. Resultados semelhantes foram obtidos por Lollato e Silva (1984) e Buitrago et al. (1991) os quais constataram que sementes de feijão beneficiadas na mesa de gravidade apresentaram melhor qualidades física, fisiológica e sanitária.

Assim, a presente pesquisa foi realizada com o objetivo de se verificar a qualidade de sementes após várias etapas do beneficiamento de dois híbridos de milho e a contribuição de cada equipamento na melhoria de qualidade das sementes.

\section{MATERIAL E MÉTODOS}

A presente pesquisa foi desenvolvida no Laboratório de Análise de Sementes da Faculdade de Engenharia de Ilha Solteira - UNESP, onde foram avaliados dois híbridos comerciais de milho. No momento da colheita das sementes foram coletadas espigas para debulha manual, as quais constituíram a testemunha sem dano, para cada um dos híbridos.

Após a colheita mecânica dos híbridos, foram retiradas do depósito graneleiro do caminhão, amostras simples de sementes, as quais geraram uma amostra composta, constituindo-se no tratamento recepção. Foram amostrados $5 \mathrm{~kg}$ de sementes, as quais foram acondicionadas em sacos de papel Kraft e colocadas em câmara seca a $22^{\circ} \mathrm{C}$ e $40 \%$ UR. Após cada etapa do beneficiamento, ou seja, das operações de secagem, pré-limpeza, limpeza, separação por espessura, mesa gravitacional e quanto as sementes encontravam-se prontas para o ensaque, sendo estas sementes coletadas após tratamento químico (Inseticida Pirimifós Metílico na dose de $16 \mathrm{~mL}$ por tonelada e o fungicida Captana na dose de $120 \mathrm{~g}$ de ingrediente ativo por $100 \mathrm{~kg}$ de sementes), foram coletadas as amostras de $5 \mathrm{~kg}$, as quais foram submetidas aos testes de avaliação da qualidade fisiológica.

Dois híbridos, XB 8010 e XB 8030, foram utilizados neste trabalho e os tratamentos foram constituídos pelas sete etapas do beneficiamento, além da testemunha (colheita e debulha manual), totalizando, constituindo-se, pois em 8 tratamentos para cada híbrido: 1 - testemunha (TEST) - sementes colhidas em espiga e debulhadas manualmente; 2 - amostra retirada na recepção das sementes após a colheita mecânica (Recepção);3 - amostra retirada após secagem (PS); 4 - amostra retirada após prélimpeza (PPL); 5 - amostra retirada após limpeza (PL); 6 - amostra retirada após separação por espessura (PSE);

7 - amostra retirada após mesa gravitacional (PMG); 8 sementes tratadas prontas para o ensaque (PR).

$\mathrm{O}$ delineamento utilizado foi $\mathrm{o}$ inteiramente casualizado com 8 tratamentos e 4 repetições, com exceção para o teste de emergência em solo que foi utilizado o delineamento em blocos ao acaso. Cada híbrido foi avaliado separadamente.

Foram utilizadas sementes chatas, da peneira $22 \mathrm{~L}$ e os testes foram iniciados após a obtenção de todas as 
amostras. As sementes foram avaliadas logo após a coleta das amostras, no mês de setembro, e após 90 dias de armazenamento Os seguintes testes foram utilizados para a avaliação fisiológica das sementes:

Análise de pureza física - foi realizada na fase inicial, coletando-se duas sub-amostras de $500 \mathrm{~g}$, conforme indicações das Regras de Análise de Sementes (Brasil, 1992), as quais foram pesadas em balança de precisão 0,1 g e colocadas sobre cartolina branca para serem separadas manualmente. Após separação, as sementes puras foram pesadas e calculou-se a porcentagem de pureza física;

Grau de umidade (GU) - determinado com quatro repetições de 50 sementes, em estufa a $105 \pm 3{ }^{\circ} \mathrm{C}$, por $24 \mathrm{~h}$ (Brasil, 1992), sendo os resultados expressos em porcentagem;

Porcentagem de germinação (G) - obtida no teste de germinação realizado com quatro sub amostras de 50 sementes por tratamento, semeadas em substrato de rolo de papel tipo Germitest umedecido com água destilada equivalente a 2,5 vezes o peso do papel seco, as quais foram levadas ao germinador modelo Mangelsdorf, à temperatura de $25^{\circ} \mathrm{C}$. A contagem das plântulas normais foi realizada aos 4 e 7 dias após a instalação do teste, conforme os critérios das Regras para Análise de Sementes (Brasil, 1992);

Primeira contagem de germinação (G1) - obtida no teste de germinação, pela contagem das plântulas normais no quarto dia após a instalação do teste, conforme metodologia descrita por Marcos Filho et al. (1987).

Índice de velocidade de germinação (IVG) - obtido no teste de germinação, computando-se as plântulas normais obtidas do quarto ao sétimo dia após a semeadura, calculado de acordo com Maguire (1962);

Porcentagem de germinação no teste de envelhecimento acelerado (EA) - obtido pelo método da mini-câmara conforme descrito por Marcos Filho et al. (1987), sendo colocadas 200 sementes sobre uma tela plástica em uma caixa gerbox modificada, contendo 40 $\mathrm{mL}$ de água destilada. A caixa foi tampada e colocada em estufa BOD regulada à temperatura de $42{ }^{\circ} \mathrm{C}$ por 96 horas. Após este período, as sementes foram semeadas em substrato papel toalha e levadas ao germinador regulado a $25^{\circ} \mathrm{C}$ por quatro dias. As contagens foram realizadas de acordo com o descrito para o teste de germinação;

Porcentagem de germinação no teste de frio (TF) - obtido pelo método do papel sem solo, sendo utilizadas quatro repetições de 50 sementes semeadas sobre papel previamente umedecido com quantidade de água equivalente a 2,5 vezes o peso do substrato seco. Após a semeadura, as sementes foram colocadas em câmara regulada a $10^{\circ} \mathrm{C}$ por sete dias e após este período em germinador regulado a temperatura de $25{ }^{\circ} \mathrm{C}$ por oito dias. Os resultados foram expressos em porcentagem de plântulas normais;

Teste de Tetrazólio (TT) - realizado em quatro subamostras de 50 sementes umedecidas entre em papel toalha úmido por 16 horas, sob temperatura de 25 a $30^{\circ} \mathrm{C}$. As sementes foram seccionadas, submersas na solução de tetrazólio e levadas à câmara com temperatura entre 30 e $40{ }^{\circ} \mathrm{C}$, e mantidas no escuro. Depois de atingida a coloração ideal dos embriões, a solução foi eliminada e as sementes foram lavadas em água corrente por diversas vezes e conservadas imersas em água até o momento da avaliação, realizada conforme metodologia proposta por Krzyzanowski et al. (1999).

Comprimento da raiz primária e da parte aérea (CRP e CPA) - valores médios foram obtidos de 20 sementes semeadas em papel umedecido e demarcado de forma longitudinal com duas linhas nas quais foram colocadas dez sementes cada uma com a camada negra orientada para baixo. Após quatro dias em germinador, foram medidos os comprimentos da raiz primária e da parte aérea, em cm;

Matéria seca das plântulas (MS) - obtido das plântulas utilizadas para medição do comprimento de raiz e de hipocótilo. O material foi colocado em sacos de papel e levado à estufa regulada a $65^{\circ} \mathrm{C}$ até atingir peso constante, quando foram obtidos os pesos com precisão de $0,001 \mathrm{~g}$.

Emergência da plântula (EP) - Conduzida mediante delineamento em blocos ao acaso. Cada repetição foi representada por uma linha de $4 \mathrm{~m}$ de comprimento, onde foram distribuídas 50 sementes, espaçadas entre si de $8 \mathrm{~cm}$, em sulcos com cerca de $7 \mathrm{~cm}$ de profundidade e cobertas com, aproximadamente, $3 \mathrm{~cm}$ de terra. $\mathrm{O}$ espaçamento entrelinhas foi de $40 \mathrm{~cm}$. Aos 14 dias após semeadura, foi efetuada a contagem, expressando-se os resultados em porcentagem de plântulas normais.

Deterioração controlada (DC) - com grau de umidade conhecido, as sementes foram mantidas em contato com água destilada em caixas plásticas do tipo gerbox para, por meio de pesagens sucessivas, serem obtidas sementes com grau de umidade de $20 \%$. Em seguida, as sementes foram colocadas em embalagem de alumínio, hermeticamente fechada e mantidas sob 10 ${ }^{\circ} \mathrm{C}$ por 12 horas para uniformizar a umidade na massa; 
posteriormente, o material permaneceu imerso em água e em "banho-maria" a $45{ }^{\circ} \mathrm{C}$, por 48 horas. Concluído este período, foi realizado o teste de germinação, com quatro repetições de 50 sementes, sendo a avaliação efetuada aos 4 dias após a semeadura. Os resultados foram expressos em porcentagem de plântulas normais.

Para a análise de variância e a comparação de médias, realizado por meio do teste de Tukey a 5\%, empregou-se o Programa de Análise Estatística - SANEST (Zonta e Machado, 1984).

\section{RESULTADOS E DISCUSSÃO}

Analisando a Tabela 1 observa-se que mesmo na recepção as sementes já apresentaram uma pequena quantidade de impurezas e que apenas com a operação de limpeza as sementes dos dois híbridos já atenderam aos valores adequados para comercialização superando o valor mínimo exigido, de $98 \%$.

TABELA 1. Valores médios de pureza física das sementes durante as fases de beneficiamento para os híbridos XB 8010 e XB 8030.

\begin{tabular}{lcc}
\hline Tratamentos & $\begin{array}{c}\text { XB 8010 } \\
(\%)\end{array}$ & $\begin{array}{c}\text { XB 8030 } \\
(\%)\end{array}$ \\
\hline Testemunha & 99 & 99,5 \\
Recepção & 94,5 & 95,5 \\
Após secagem & 96 & 95,5 \\
Após pré-limpeza & 97 & 96,5 \\
Após limpeza & 99,5 & 100 \\
Após separação & 99,5 & 99,5 \\
Após mesa gravitacional & 99,5 & 99,5 \\
Sementes prontas & 100 & 100 \\
\hline
\end{tabular}

Isto atesta a eficiência da operação indicando que para estes dois híbridos algumas das operações subsequentes podem até serem suprimidas. No entanto, conforme Menezes et al. (2002) a classificação é necessária em sementes de milho devido à grande variação de tamanho, forma e qualidade das sementes em função da posição na espiga; sendo que a uniformidade de forma e tamanho é muito importante para facilitar tratamentos com fungicidas e semeadura.

$\mathrm{Na}$ Tabela 2, de acordo com os resultados pode- se observar que as sementes estavam com teor de água baixo em todas as fases de beneficiamento, estando mais suscetíveis aos danos mecânicos, principalmente por quebramento. Segundo Jijon e Barros (1983), um dos fatores que influenciam a susceptibilidade das sementes ao dano mecânico é o seu grau de umidade. Verifica-se também que ao longo das fases de beneficiamento ocorreu um aumento na porcentagem de germinação na primeira contagem, chegando a $79 \%$ quando a semente já estava pronta para ser ensacada. Os resultados das sementes do tratamento testemunha e dos demais pontos foram menos vigorosas do que as sementes prontas embora não tenham diferido estatisticamente (Tabela 2). Houve certa incoerência nesses resultados, já que as sementes do tratamento testemunha foram colhidas em espiga e debulhadas manualmente, consequentemente, são sementes que aparentemente não tinham nenhum dano físico, o que provavelmente acarreta uma germinação de forma mais rápida e uniforme, mas não é só injúria física que interfere na germinação, essas sementes podem ter sofrido algum estresse pós-colheita que não foi percebido e com isto não apresentou um desempenho adequado. Além disso, o tratamento testemunha apresentava sementes de todos os tamanhos e espessura, já que não houve nenhum tipo de separação durante a debulha manual, e essa desuniformidade pode ser um fator de diferença de desempenho.

Ao analisar os dados, pode-se constatar que para germinação e velocidade de germinação os resultados foram semelhantes, ou seja, houve diferença significativa entre os tratamentos para os dois híbridos, evidenciando que a germinação e velocidade de germinação foram altas em todas as etapas, com exceção do tratamento recepção. Esses resultados mostram o efeito positivo do beneficiamento para o potencial fisiológico das sementes.

Os valores encontrados para as avaliação da qualidade das sementes, na recepção, foram os mais baixos, esse fato pode ser explicado pela alta quantidade de sementes trincadas, quebradas e rachadas existentes na amostra, e esse dano na semente provoca elevada redução no poder germinativo da semente. Verifica-se que após as sementes passarem pela mesa de gravidade ocorre um ligeiro aumento na porcentagem de germinação, primeira contagem da germinação e no índice velocidade de germinação, com isso pode-se dizer que a mesa de gravidade interfere positivamente na qualidade fisiológica das sementes, ao remover as sementes de menor densidade, quebradas e atacadas por patógenos. Resultados semelhantes foram obtidos por Fessel et al., 2003. 
TABELA 2. Valores médios de grau de umidade, primeira contagem, germinação e velocidade de germinação das sementes após cada fase de beneficiamento e em duas épocas de armazenamento, para o híbrido XB 8010.

\begin{tabular}{|c|c|c|c|c|c|c|c|c|c|}
\hline \multicolumn{10}{|c|}{ Tratamentos } \\
\hline & TEST. & Recepção & PS & PPL & PL & PSE & PMG & PR & \\
\hline Época $^{1}$ & \multicolumn{8}{|c|}{ Grau de umidade (\%) } & Médias \\
\hline 1 & 9 & 9,5 & 9,3 & 9 & 9,8 & 9,5 & 9 & 9,5 & $9,3 b$ \\
\hline 2 & 9 & 8,9 & 9 & 9,5 & 9,8 & 10,8 & 9,8 & 10 & $9,6^{\mathrm{a}}$ \\
\hline Médias & $9,0 \mathrm{c}$ & $9,1 b c$ & $9,1 \mathrm{bc}$ & $9,3 \mathrm{bc}$ & $9,8 \mathrm{ab}$ & $10,1 \mathrm{a}$ & $9,4 b c$ & $9,8 \mathrm{ab}$ & \\
\hline $\mathrm{CV}(\%)$ & 4,96 & & & & & & & & \\
\hline Época $^{1}$ & \multicolumn{8}{|c|}{ Primeira contagem de germinação(\%) } & Médias \\
\hline 1 & 77 & 66 & 67 & 66 & 71 & 77 & 80 & 73 & $72^{\mathrm{a}}$ \\
\hline 2 & 66 & 63 & 68 & 70 & 69 & 73 & 74 & 85 & $71^{\mathrm{a}}$ \\
\hline Médias & $69 \mathrm{abc}$ & $64 c$ & $68 \mathrm{bc}$ & $69 \mathrm{bc}$ & $70 \mathrm{abc}$ & $75 \mathrm{abc}$ & $77 \mathrm{ab}$ & $79 a$ & \\
\hline $\mathrm{CV}(\%)$ & 7,83 & & & & & & & & \\
\hline Época & \multicolumn{8}{|c|}{ Germinação (\%) } & Médias \\
\hline 1 & 94 & 90 & 93 & 93 & 94 & 98 & 97 & 95 & $94^{\mathrm{a}}$ \\
\hline 2 & 92 & 74 & 95 & 95 & 91 & 97 & 92 & 100 & $93^{\mathrm{a}}$ \\
\hline Médias & $93 \mathrm{ab}$ & $83 b$ & $94 \mathrm{a}$ & $94 \mathrm{a}$ & $93 \mathrm{ab}$ & $97 \mathrm{a}$ & $95 \mathrm{a}$ & $98 \mathrm{a}$ & \\
\hline $\mathrm{CV}(\%)$ & 7,84 & & & & & & & & \\
\hline Época & \multicolumn{8}{|c|}{ Velocidade de germinação } & Médias \\
\hline 1 & 10,3 & 9,8 & 9,8 & 10 & 10 & 10,5 & 10,5 & 10,3 & $10,1^{\mathrm{a}}$ \\
\hline 2 & 9,3 & 8,3 & 9,3 & 10 & 9,8 & 10 & 9,8 & 11,5 & $9,7^{\mathrm{a}}$ \\
\hline Médias & $9,8 \mathrm{ab}$ & $9,0 \mathrm{~b}$ & $9,5 b$ & $10,0 \mathrm{~b}$ & $9,9 \mathrm{ab}$ & $10,3 \mathrm{ab}$ & $10,1 \mathrm{ab}$ & $10,9 \mathrm{a}$ & \\
\hline $\mathrm{CV}(\%)$ & 8,45 & & & & & & & & \\
\hline
\end{tabular}

${ }^{1}$ Época 1 - avaliação antes do armazenamento; Época 2 - avaliação após 90 dias de armazenamento. Médias seguidas pela mesma letra, na linha ou na coluna, não diferem entre si, pelo teste de Tukey a $5 \%$ de probabilidade.

Considerando que o padrão mínimo para comercialização das sementes é de $80 \%$, tem-se que o híbrido XB 8010 apresentou em todos os tratamentos a germinação superior aos padrões pré-estabelecidos, sendo que a média situou ao redor de $93 \%$ (Tabela 2).

Nas duas épocas de avaliação das sementes, ou seja, antes e após noventa dias de armazenamento, não houve diferença significativa, indicando que as sementes conservaram o seu poder germinativo.

O teste de tetrazólio tem se mostrado uma alternativa promissora pela precisão e rapidez na determinação da viabilidade e do vigor da semente, e de acordo com os resultados verifica-se alta viabilidade de sementes colhidas em espiga, que apresentou 99,5\% de sementes viáveis
(Tabela 3). No decorrer das fases de beneficiamento verifica-se que houve um aumento na porcentagem de sementes viáveis a cada etapa, sendo que a partir da mesa de gravidade não houve diferença para a testemunha, mostrando a eficiência das máquinas de beneficiamento, na eliminação de sementes não viáveis da amostra.

Segundo Marcos Filho (2005) as sementes são estruturas capazes de sobreviver e manter a viabilidade até que o clima e o local sejam favoráveis para o início de uma nova geração, mas as condições em que as sementes foram impostas no teste de deterioração controlada causaram forte queda no poder germinativo das sementes ao longo das fases de beneficiamento (Tabela 4). 
TABELA 3. Resultados dos testes de tetrazólio e emergência de plântula em solo obtidos de sementes de milho, híbridos XB 8010, em cada etapa de beneficiamento e em duas épocas de avaliação.

\begin{tabular}{|c|c|c|c|c|c|c|c|c|c|}
\hline \multicolumn{10}{|c|}{ Tratamentos } \\
\hline & TEST & Recepção & PS & PPL & PL & PSE & PMG & PR & \\
\hline Época $^{1}$ & \multicolumn{8}{|c|}{ Viabilidade (\%) } & Médias \\
\hline 1 & 100 & 89 & 93 & 89 & 97 & 99 & 100 & 98 & $97^{\mathrm{a}}$ \\
\hline 2 & 99 & 79 & 92 & 83 & 92 & 86 & 90 & 97 & $91 b$ \\
\hline Médias & $100 \mathrm{a}$ & $84 \mathrm{c}$ & $93 b c$ & $86 c$ & $95 b$ & $94 b$ & $97 \mathrm{~b}$ & $97 \mathrm{ab}$ & \\
\hline $\mathrm{CV}(\%)$ & 6,41 & & & & & & & & \\
\hline Época & \multicolumn{8}{|c|}{ Emergência de Plântula em Solo (\%) } & Médias \\
\hline 1 & 86 & 74 & 83 & 78 & 86 & 81 & 84 & 83 & $82^{a}$ \\
\hline 2 & 85 & 69 & 77 & 76 & 83 & 86 & 82 & 79 & $80^{\mathrm{a}}$ \\
\hline Médias & $88 \mathrm{a}$ & $84 a$ & $83 a b$ & $84 a b$ & $81 \mathrm{ab}$ & $80 a b$ & $77 \mathrm{bc}$ & $71 \mathrm{c}$ & \\
\hline $\mathrm{CV}(\%)$ & 5,36 & & & & & & & & \\
\hline
\end{tabular}

1 Época 1 - avaliação antes do armazenamento; Época 2 - avaliação após 90 dias de armazenamento. Médias seguidas pela mesma letra, na linha ou na coluna, não diferem entre si, pelo teste de Tukey a $5 \%$ de probabilidade.

TABELA 4. Resultados dos testes de envelhecimento acelerado, frio e deterioração controlada obtidos de sementes de milho, híbridos XB 8010, em cada etapa de beneficiamento e em duas épocas de avaliação.

\begin{tabular}{|c|c|c|c|c|c|c|c|c|c|}
\hline \multicolumn{10}{|c|}{ Tratamentos } \\
\hline & TEST & Recepção & PS & PPL & PL & PSE & PMG & PR & \\
\hline Época $^{1}$ & \multicolumn{8}{|c|}{ Envelhecimento Acelerado (\%) } & Médias \\
\hline 1 & 92 & 84 & 93 & 88 & 88 & 84,3 & 89 & 93 & $89 \mathrm{a}$ \\
\hline 2 & 97 & 80 & 68 & 78 & 71 & 91,1 & 62 & 97 & $83 b$ \\
\hline Médias & $95 \mathrm{a}$ & $82 b$ & $82 b$ & $83 b$ & $79,8 b$ & $88 \mathrm{ab}$ & $77 \mathrm{~b}$ & $95 \mathrm{a}$ & \\
\hline $\mathrm{CV}(\%)$ & 9,86 & & & & & & & & \\
\hline Época & \multicolumn{8}{|c|}{ Teste de Frio (\%) } & Médias \\
\hline 1 & 86 & 75 & 75 & 85 & 81 & 79 & 88 & 91 & $83 a$ \\
\hline 2 & 85 & 76 & 77 & 80 & 81 & 84 & 89 & 93 & $84 a$ \\
\hline Médias & $86 a b c$ & $76 \mathrm{~d}$ & $76 \mathrm{~cd}$ & $82 \mathrm{bd}$ & $81 \mathrm{bcd}$ & $81 \mathrm{bcd}$ & $89 \mathrm{ab}$ & $92 a$ & \\
\hline $\mathrm{CV}(\%)$ & 7,14 & & & & & & & & \\
\hline Época & \multicolumn{8}{|c|}{ Deterioração Controlada (\%) } & Médias \\
\hline 1 & 84 & 90 & 93 & 82 & 81 & 94 & 94 & 77 & $87 a$ \\
\hline 2 & 90 & 74 & 83 & 86 & 70 & 92 & 77 & 81 & $82 b$ \\
\hline Médias & $87 \mathrm{ab}$ & $83 \mathrm{bc}$ & $88 \mathrm{ab}$ & $84 b c$ & $76 c$ & $93 a$ & $86 a b c$ & $79 b c$ & \\
\hline $\mathrm{CV}(\%)$ & 7,57 & & & & & & & & \\
\hline
\end{tabular}

${ }^{1}$ Época 1 - avaliação antes do armazenamento; Época 2 - avaliação após 90 dias de armazenamento. Médias seguidas pela mesma letra, na linha ou na coluna, não diferem entre si, pelo teste de Tukey a $5 \%$ de probabilidade. 
A deterioração pode ser definida como um processo que envolve mudanças citológicas, bioquímicas, fisiológicas e físicas que conduzem à morte das sementes. O processo deteriorativo das sementes é a principal causa do prejuízo à sua viabilidade e vigor, podendo influenciar o rendimento de uma cultura pelo decréscimo na germinação, estabelecendo uma baixa população plantas por unidade de área e resultando em menor desempenho das plantas sobreviventes (Roberts, 1974).

Este fato pode ser visualizado nos resultados do teste de emergência em solo, onde a deterioração afetou a porcentagem de emergência das sementes do híbrido XB 8010, coletadas após cada fase do beneficiamento, inclusive na fase de sementes prontas para o ensacamento, que obteve apenas $71,3 \%$ de emergência (Tabela 3).

Analisando os dados de envelhecimento acelerado, verifica-se que não ocorreu variação estatística nos resultados e vigor das sementes do tratamento recepção até mesa gravitacional para o híbrido XB 8010, sendo que nessas etapas o vigor das sementes foi menor (Tabela 4). Os danos mecânicos provocados pela colheita, além das condições extremas impostas pelo teste de envelhecimento acelerado, como alta temperatura e alta umidade, explicam este fato, sendo menos significativo nas sementes prontas para ensaque, que não diferiram estatisticamente da testemunha para os dois híbridos. Paiva et al. 2000, verificaram que no teste de envelhecimento acelerado as sementes procedentes da colheita com debulha manual (testemunha) foram superiores às coletadas após as etapas de beneficiamento.

De acordo com os resultados da Tabela 4 verificase que no teste de frio houve diferença significativa entre os tratamentos e uma maior variação no vigor das sementes ao longo das etapas de beneficiamento. As sementes do tratamento recepção foram as mais afetadas pelas condições impostas pelo teste de frio para o híbrido XB 8010. Após mesa gravitacional houve uma melhoria na qualidade fisiológica das sementes, que apresentaram maior vigor no tratamento sementes prontas para ensaque (92\%) (Tabela 4). Menezes et al. (2002) verificaram que o melhor resultado de vigor avaliado pelo teste de frio foi verificado após a prélimpeza.

Os resultados indicam que o teste de envelhecimento acelerado e o teste de frio tiveram comportamento bastante similar (Tabela 4), e que tanto no envelhecimento acelerado quanto no teste de frio as sementes tiveram melhor desempenho na última etapa, evidenciando que o tratamento das sementes contribui para a melhoria da qualidade fisiológica das sementes, ou seja, protege as sementes do ataque de patógenos e, além disso, na última etapa as sementes já passaram por todos os equipamentos, onde foram retiradas as sementes mais leves, as que possam ter sofrido algum dano por insetos, além das sementes quebradas. Esses resultados atestam a importância do beneficiamento, devido à melhoria na qualidade final das sementes e com isso o híbrido XB 8010 tem capacidade de apresentar desempenho adequado quando expostas a condições diferentes de ambiente, podendo resistir à baixa temperatura em condições de semeadura, além de ter potencial para resistir ao armazenamento.

Observa-se na Tabela 5 que não ocorreram diferenças significativas entre tratamentos para matéria seca de plântulas e comprimento de raiz primária, para o híbrido XB 8010. Já para comprimento da parte aérea a testemunha apresentou melhor desempenho, com maior crescimento $(7,1 \mathrm{~cm})$, mas não diferiu dos demais tratamentos ao longo das fases de beneficiamento, com exceção para sementes prontas para ensacamento, que apresentou menor comprimento de parte aérea $(5,8 \mathrm{~cm})$.

Os dados evidenciam que não houve diferença significativa nos testes que avaliam o crescimento da plântula nas duas épocas de avaliação.

Os valores de teor de água também foram bastante baixos para as sementes do híbrido XB $8030 \mathrm{em}$ todas as fases de beneficiamento, não ultrapassando $9,5 \%$ (Tabela $6)$.

Os resultados também mostraram o efeito positivo do beneficiamento na qualidade das sementes com as sementes prontas para serem comercializadas sempre apresentando um alto desempenho. O bom desempenho das sementes em relação ao material obtido na recepção indicou que a retirada de impurezas beneficiou a qualidade das sementes, e que as sementes prontas apresentaram desempenho satisfatório (Tabela 7). Verificou-se também pequena redução na qualidade das sementes quando se compararam os resultados obtidos na primeira época de avaliação em relação a segunda. Mesmo com as possibilidades de danos mecânicos durante as etapas do beneficiamento verifica-se que ocorreu melhoria da qualidade das sementes ao comparar os resultados com a condição inicial (recepção). 
TABELA 5. Resultados de matéria seca, comprimento da raiz primária e comprimento da parte aérea obtidos de plântulas de milho, híbridos XB XB 8010, em cada etapa de beneficiamento e em duas épocas de avaliação.

\begin{tabular}{|c|c|c|c|c|c|c|c|c|c|}
\hline \multicolumn{10}{|c|}{ Tratamentos } \\
\hline & TEST & Recepção & PS & PPL & PL & PSE & PMG & PR & \\
\hline Época $^{1}$ & \multicolumn{8}{|c|}{ Matéria Seca (mg) } & Médias \\
\hline 1 & 0,5 & 0,4 & 0,4 & 0,4 & 0,3 & 0,5 & 0,4 & 0,4 & $0,4^{\mathrm{a}}$ \\
\hline 2 & 0,3 & 0,2 & 0,4 & 0,3 & 0,3 & 0,3 & 0,4 & 0,4 & $0,3^{\mathrm{a}}$ \\
\hline Médias & $0,4 \mathrm{a}$ & $0,3 \mathrm{a}$ & $0,4 \mathrm{a}$ & $0,3 \mathrm{a}$ & $0,3 \mathrm{a}$ & $0,4 \mathrm{a}$ & $0,4 \mathrm{a}$ & $0,4 a$ & \\
\hline $\mathrm{CV}(\%)$ & 20,6 & & & & & & & & \\
\hline Época & \multicolumn{8}{|c|}{ Comprimento da Raiz Primária $(\mathrm{cm})$} & Médias \\
\hline 1 & 15,8 & 12,5 & 13,3 & 13,3 & 13 & 13 & 12,5 & 13,8 & $13,4^{\mathrm{a}}$ \\
\hline 2 & 14,3 & 14 & 12,8 & 12,8 & 11,5 & 12,8 & 12 & 13,5 & $12,9^{\mathrm{a}}$ \\
\hline Médias & $15,0 \mathrm{a}$ & $13,3 \mathrm{a}$ & $13,0 \mathrm{a}$ & $13,0 \mathrm{a}$ & $12,3 \mathrm{a}$ & $12,9 \mathrm{a}$ & $12,3 \mathrm{a}$ & $13,6 \mathrm{a}$ & \\
\hline $\mathrm{CV}(\%)$ & 17,8 & & & & & & & & \\
\hline Época & \multicolumn{8}{|c|}{ Comprimento da Parte Aérea $(\mathrm{cm})$} & Médias \\
\hline 1 & 6,3 & 5,5 & 5,8 & 6,5 & 7,5 & 8 & 7,5 & 6,3 & $6,7^{\mathrm{a}}$ \\
\hline 2 & 7,3 & 6 & 6,3 & 6 & 6,3 & 8,3 & 6,5 & 7 & $6,4^{\mathrm{a}}$ \\
\hline Médias & $7,1 \mathrm{a}$ & $7,0 \mathrm{ab}$ & $6,8 \mathrm{ab}$ & $6,9 \mathrm{ab}$ & $6,6 a b$ & $6,3 a b$ & $6,0 \mathrm{ab}$ & $5,8 \mathrm{~b}$ & \\
\hline $\mathrm{CV}(\%)$ & 12,9 & & & & & & & & \\
\hline
\end{tabular}

${ }^{1}$ Época 1 - avaliação antes do armazenamento; Época 2 - avaliação após 90 dias de armazenamento. Médias seguidas pela mesma letra, na linha ou na coluna, não diferem entre si, pelo teste de Tukey a $5 \%$ de probabilidade. 
TABELA 6. Valores médios de teor de água, primeira contagem, germinação e velocidade de germinação de sementes após cada fase de beneficiamento e em duas épocas de armazenamento, para o híbrido XB 8030.

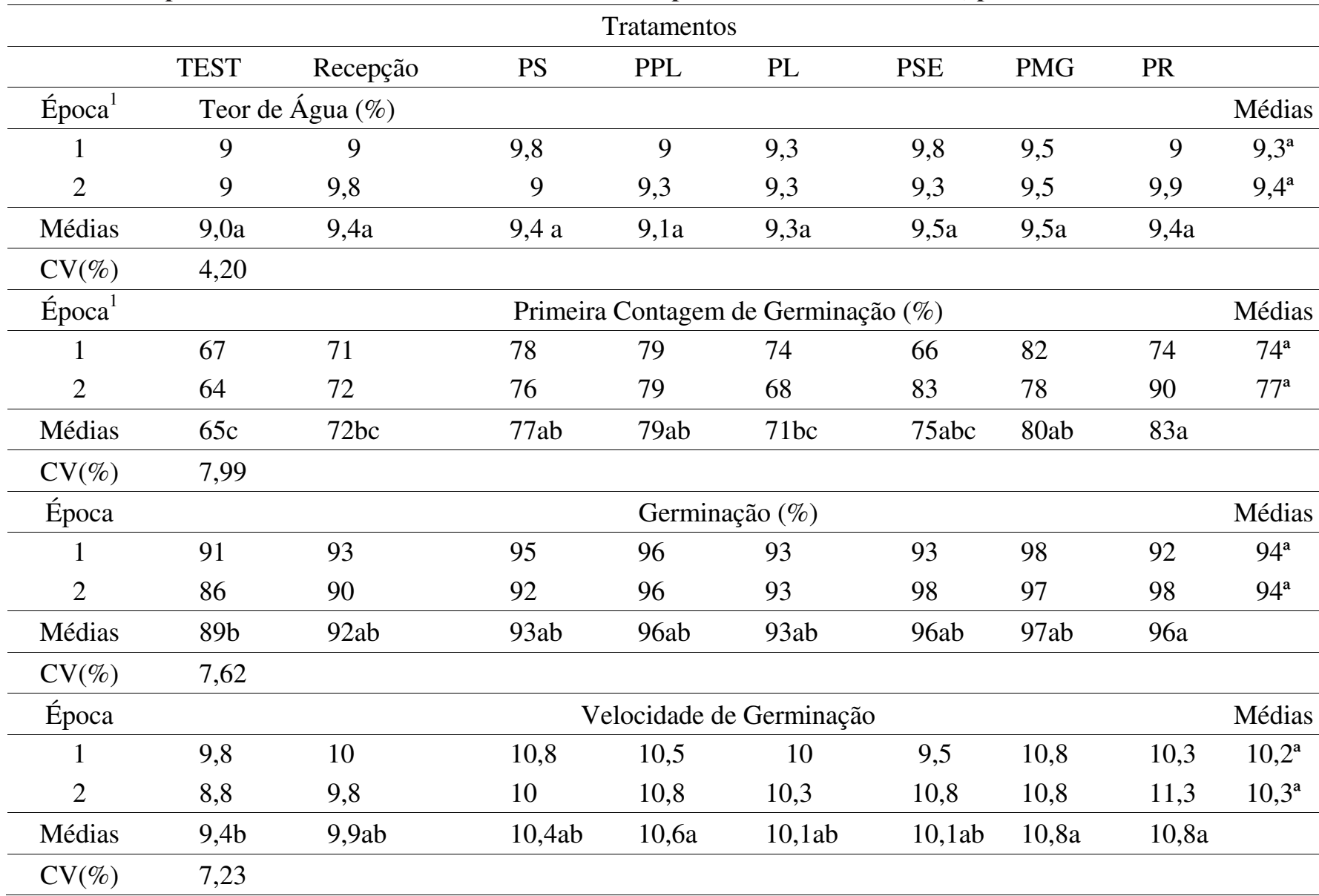

${ }^{1}$ Época 1 - avaliação antes do armazenamento; Época 2 - avaliação após 90 dias de armazenamento. Médias seguidas pela mesma letra, na linha ou na coluna, não diferem entre si, pelo teste de Tukey a $5 \%$ de probabilidade.

TABELA 7. Resultados dos testes de tetrazólio e emergência de plântula em solo obtidos de sementes de milho, híbridos XB 8030, em cada etapa de beneficiamento e em duas épocas de avaliação.

\begin{tabular}{|c|c|c|c|c|c|c|c|c|c|}
\hline \multicolumn{10}{|c|}{ Tratamentos } \\
\hline & TEST & Recepção & PS & PPL & PL & PSE & PMG & PR & \\
\hline Época $^{1}$ & \multicolumn{8}{|c|}{ Viabilidade $(\%)$} & Médias \\
\hline 1 & 98 & 86 & 93 & 90 & 91 & 96 & 100 & 100 & $95 \mathrm{a}$ \\
\hline 2 & 95 & 74 & 91 & 83 & 88 & 89 & 90 & 95 & $89 \mathrm{~b}$ \\
\hline Médias & $97 \mathrm{ab}$ & $81 \mathrm{~d}$ & $92 \mathrm{bc}$ & $87 \mathrm{~cd}$ & $90 \mathrm{c}$ & $93 \mathrm{bc}$ & $96 \mathrm{ab}$ & $98 \mathrm{a}$ & \\
\hline $\mathrm{CV}(\%)$ & 5,57 & & & & & & & & \\
\hline Época & \multicolumn{8}{|c|}{ Emergência de Plântula em Solo (\%) } & Médias \\
\hline 1 & 83 & 72 & 91 & 79 & 92 & 86 & 89 & 92 & $86 a$ \\
\hline 2 & 78 & 70 & 85 & 76 & 89 & 78 & 82 & 84 & $81 \mathrm{~b}$ \\
\hline Médias & $81 b c$ & $1 d$ & $88 \mathrm{ab}$ & $78 \mathrm{~cd}$ & $91 \mathrm{a}$ & $82 \mathrm{bc}$ & $86 a b c$ & $88 \mathrm{ab}$ & \\
\hline $\mathrm{CV}(\%)$ & 6,07 & & & & & & & & \\
\hline
\end{tabular}

${ }^{1}$ Época 1 - avaliação antes do armazenamento; Época 2 - avaliação após 90 dias de armazenamento. Médias seguidas pela mesma letra, na linha ou na coluna, não diferem entre si, pelo teste de Tukey a 5\% de probabilidade. 
O vigor, avaliado por meio dos testes de envelhecimento acelerado, teste de frio e deterioração controlada, para o híbrido XB 8030 (Tabela 8), confirma o melhor desempenho das sementes prontas evidenciando nas duas épocas de avaliação que o beneficiamento promoveu uma sensível melhoria na qualidade das sementes até mesmo quando se compara com a testemunha, cujo processo de colheita e debulha foi manual, indicando que os processos de retirada de algumas sementes mais leves e/ou que possam ter sofrido algum dano por insetos resultou em melhoria na qualidade final. Menezes et al. 2002 verificaram que o melhor resultado de vigor avaliado pelo teste de frio foi verificado após a pré-limpeza.

TABELA 8. Resultados dos testes de envelhecimento acelerado, frio e deterioração controlada obtidos de sementes de milho, híbrido XB 8030, em cada etapa de beneficiamento e em duas épocas de avaliação.

\begin{tabular}{|c|c|c|c|c|c|c|c|c|c|}
\hline \multicolumn{10}{|c|}{ Tratamentos } \\
\hline & TEST & Recepção & PS & PPL & PL & PSE & PMG & PR & \\
\hline Época $^{1}$ & \multicolumn{8}{|c|}{ Envelhecimento acelerado (\%) } & Médias \\
\hline 1 & 89 & 88 & 78 & 83 & 82 & 80 & 87 & 93 & $85 a$ \\
\hline 2 & 93 & 78 & 83 & 87 & 82 & 86 & 86 & 94 & $87 a$ \\
\hline Médias & $91 \mathrm{ab}$ & $83 b$ & $81 \mathrm{ab}$ & $85 \mathrm{ab}$ & $82 \mathrm{~b}$ & $83 \mathrm{~b}$ & $87 \mathrm{ab}$ & $94 a$ & \\
\hline $\mathrm{CV}(\%)$ & 8,71 & & & & & & & & \\
\hline Época & \multicolumn{8}{|c|}{ Teste de frio $(\%)$} & Médias \\
\hline 1 & 82 & 68 & 74 & 71 & 81 & 70 & 82 & 83 & $77 \mathrm{~b}$ \\
\hline 2 & 80 & 80 & 71 & 78 & 78 & 80 & 83 & 91 & $81 \mathrm{a}$ \\
\hline Médias & $81 \mathrm{ab}$ & $74 \mathrm{~b}$ & $73 b$ & $75 b$ & $80 \mathrm{ab}$ & $75 b$ & $83 \mathrm{ab}$ & $88 \mathrm{a}$ & \\
\hline $\mathrm{CV}(\%)$ & 7,87 & & & & & & & & \\
\hline Época & \multicolumn{8}{|c|}{ Deterioração controlada (\%) } & Médias \\
\hline 1 & 87 & 84 & 93 & 74 & 91 & 90 & 88 & 94 & $88 \mathrm{a}$ \\
\hline 2 & 77 & 62 & 89 & 65 & 91 & 63 & 80 & 93 & $79 b$ \\
\hline Médias & $83 \mathrm{bc}$ & $74 \mathrm{~cd}$ & $91 \mathrm{ab}$ & $69 d$ & $91 \mathrm{ab}$ & $78 \mathrm{~cd}$ & $84 \mathrm{bc}$ & $93 \mathrm{a}$ & \\
\hline $\mathrm{CV}(\%)$ & 7,73 & & & & & & & & \\
\hline
\end{tabular}

${ }^{1}$ Época 1 - avaliação antes do armazenamento; Época 2 - avaliação após 90 dias de armazenamento. Médias seguidas pela mesma letra, na linha ou na coluna, não diferem entre si, pelo teste de Tukey a $5 \%$ de probabilidade.

No presente trabalho algumas variações nos resultados indicaram benefícios mais consistentes para as sementes após mesa gravitacional e sementes prontas para o ensaque, onde, para os três testes (EA, TF e DC) evidenciou-se o maior vigor.

Os resultados obtidos para matéria seca de plântulas, comprimento radiculada raiz primária e comprimento da parte aérea (Tabela 9) para o híbrido XB 8030, mostram que não foram verificadas diferenças significativas entre os tratamentos, indicando que nestas duas épocas de avaliação as diferenças de vigor das sementes ainda não haviam se manifestado nas plântulas obtidas.

Conforme Marcos Filho(2005) algumas manifestações da deterioração são a redução do crescimento da plântula, aumentando a taxa de anormalidade, associada à morte de tecidos ou a distúrbios durante o crescimento. Os dados obtidos mostram que, de modo geral, as plântulas obtidas apresentaram um crescimento vigoroso para todos os tratamentos evidenciando que até os 90 dias de armazenamento, para estes três métodos de avaliação, não foram detectados os efeitos deletérios de vigor das sementes, principalmente daquelas obtidas na recepção. 
TABELA 9. Resultados dos testes de matéria seca, comprimento da raiz primária e comprimento da parte aérea de plântulas de milho, híbridos XB XB 8030, em cada etapa de beneficiamento e em duas épocas de avaliação.

\begin{tabular}{|c|c|c|c|c|c|c|c|c|c|}
\hline \multicolumn{10}{|c|}{ Tratamentos } \\
\hline & TEST & Recepção & PS & PPL & PL & PSE & PMG & PR & \\
\hline Época & \multicolumn{8}{|c|}{ Matéria Seca (mg) } & Médias \\
\hline 1 & 0,5 & 0,4 & 0,4 & 0,4 & 0,4 & 0,5 & 0,4 & 0,5 & $0,4 \mathrm{a}$ \\
\hline 2 & 0,4 & 0,4 & 0,4 & 0,4 & 0,5 & 0,4 & 0,5 & 0,3 & $0,4 a$ \\
\hline Médias & $0,4 \mathrm{a}$ & $0,4 \mathrm{a}$ & $0,4 \mathrm{a}$ & $0,4 \mathrm{a}$ & $0,5 \mathrm{a}$ & $0,5 \mathrm{a}$ & $0,4 \mathrm{a}$ & $0,4 \mathrm{a}$ & \\
\hline $\mathrm{CV}(\%)$ & 16,52 & & & & & & & & \\
\hline Época & \multicolumn{8}{|c|}{ Comprimento da Raiz Primária $(\mathrm{cm})$} & Médias \\
\hline 1 & 14,5 & 12,5 & 13 & 11 & 12,8 & 12,3 & 14 & 12,8 & $12,8 \mathrm{a}$ \\
\hline 2 & 13,8 & 12 & 13 & 12,8 & 12 & 15,3 & 12,5 & 13,3 & $13,1 \mathrm{a}$ \\
\hline Médias & $14,1 \mathrm{a}$ & $12,3 \mathrm{a}$ & $13,0 \mathrm{a}$ & $11,9 \mathrm{a}$ & $12,4 \mathrm{a}$ & $13,8 \mathrm{a}$ & $13,3 \mathrm{a}$ & $13,0 \mathrm{a}$ & \\
\hline $\mathrm{CV}(\%)$ & 17,30 & & & & & & & & \\
\hline Época & \multicolumn{8}{|c|}{ Comprimento da Parte Aérea $(\mathrm{cm})$} & Médias \\
\hline 1 & 5,5 & 5,8 & 5,8 & 6,5 & 4,5 & 5,8 & 5,8 & 6 & $5,7 \mathrm{a}$ \\
\hline 2 & 5,8 & 5,8 & 6,8 & 6 & 6,3 & 5,5 & 6,5 & 6 & $6,1 \mathrm{a}$ \\
\hline Médias & $5,6 \mathrm{a}$ & $5,8 \mathrm{a}$ & $6,3 a$ & $6,3 \mathrm{a}$ & $5,4 \mathrm{a}$ & $5,6 \mathrm{a}$ & $6,1 \mathrm{a}$ & $6,0 \mathrm{a}$ & \\
\hline $\mathrm{CV}(\%)$ & 14,50 & & & & & & & & \\
\hline
\end{tabular}

${ }^{1}$ Época 1 - avaliação antes do armazenamento; Época 2 - avaliação após 90 dias de armazenamento. Médias seguidas pela mesma letra, na linha ou na coluna, não diferem entre si, pelo teste de Tukey a 5\% de probabilidade.

\section{CONCLUSÕES}

O beneficiamento promove melhoria na qualidade das sementes de milho e as sementes obtidas após a mesa gravitacional e prontas para ensaque apresentam melhor desempenho.

\section{REFERÊNCIAS}

AMARAL, A.S.; BICCA, L.H.F.; WOBETO, L.A. Classificação de sementes de ervilha. Lavoura Arrozeira, v.348, p.32-35, 1984.

BRASIL. Ministério da Agricultura e Reforma Agrária. Secretaria Nacional de Defesa Agropecuária. Departamento Nacional de Defesa Vegetal. Coordenação de Laboratório Vegetal. Regras para análise de sementes. Brasília, DF, 1992. 365p.

BUITRAGO, I.C.; VILLELA, F.; TILLMANN, M. A.A.; SILVA, J.B. Perdas e qualidade de sementes de feijão beneficiadas em máquinas de ventiladores e peneiras e mesa de gravidade. Revista Brasileira de Sementes, v.13, n.2, p.99-104, 1991.

FESSEL. S.A.; SADER. R.; PAULA. R.C.; GALLI. J.A. Avaliação da qualidade física, fisiológica e sanitária de sementes de milho durante o beneficiamento. Revista Brasileira de Sementes, v.25, n.2, 2003.

FRANÇA-NETO, J.B.; HENNING, A.A.; KRZYZANOWSKI, F.C. Seed production and technology for the tropics. In: Tropical ropical soybean - improvement and production. EMBRAPA -CNPSo. Plant Production and Protection Series n. 27. Rome:FAO. p.217-240. 1994.

JIJON, A.V.; BARROS, A.C.S.A. Efeito dos danos mecânicos na semeadura sobre a qualidade de sementes de soja (Glycine max (L.) Merril. Tecnologia de Sementes, v.6, n.1/2, p.3-22, 1983.

KRZYZANOWSKI, F.C.; VIEIRA, R.D.; FRANÇA NETO, J.B. (Ed.). Vigor de sementes: conceitos e testes. Londrina: Abrates, 1999. 218p. 
LOLLATO, M.A.; SILVA, W.R. Efeito da utilização da mesa de gravitacional na qualidade de sementes de feijão. Pesquisa Agropecuária Brasileira, v.19, n.12, p.14831496, 1984.

MAGUIRE, J.D. Speed germination - aid index in selection and evaluation seedlings vigor. Crop Science, v.1, n.2, p.161-62, 1962.

MARCOS FILHO, J. Fisiologia de sementes de plantas cultivadas. Piracicaba: FEALQ, 2005. 495p.

MARCOS FILHO, J.; CÍCERO, S.M., SILVA, W.R. Avaliação da qualidade das sementes. Piracicaba: FEALQ, 1987. 230p.
MENEZES, N.L.; LERSCH-JUNIOR, I.; STORCK, L. Qualidade física e fisiológica das sementes de milho após beneficiamento. Revista Brasileira de Sementes, v.24, n.1, p.97-102, 2002.

PAIVA, L.E.; MEDEIROS, S.F.; FRAGA, A.C. Beneficiamento de sementes de milho colhidas mecanicamente em espigas: efeitos sobre danos mecânicos e qualidade fisiológica. Ciência Agrotécnica, v.24, p.846$856,2000$.

ROBERTS, E.H. Loss of viability and crop yields. In: ROBERTS, E.H. (Ed.). Viability of seeds. London: Chapman and Hall, 1974. p.307-320.

ZONTA, E.P.; MACHADO, A.A. SANEST: Sistema de análise estatística para microcomputadores. Pelotas: UFPel, 1984. 138p. 